\title{
Simulation Analysis of Wireless Power Transfer for Future Office Communication Systems
}

\author{
Lala Bhaskar, Pradeep Kumar, Kishore Naik Mude
}

\begin{abstract}
A Wireless Power Transfer system consists of a transmitter coil which is inductively coupled with secondary coil and is popular for wireless charging of future office communication system. Wireless power transfer is used in different applications ranging from mobile chargers to charging stations. In this paper simulation of Wireless Power Transfer for future office communication systems has been conducted over Maxwell 3d of Ansys electromagnetic suite. The input frequency of primary coil is varied from $1 \mathrm{kHz}-120 \mathrm{kHz}$ with respect to the change in resonant capacitance and observed that input frequency between $20 \mathrm{kHz}-30 \mathrm{kHz}$, the output power in secondary coil appears to be maximum at variable distances between transmitter coil and receiver coil. There is an improvement of $72 \%$ seen in the output power of secondary coil for $25 \mathrm{kHz}$ input frequency of primary coil as compared with $40 \mathrm{kHz}$ input frequency. This model can be helpful to design future Office Communication systems for charging the mobile phones, Laptops and to turn on the printer wirelessly.
\end{abstract}

Index Terms: Communication System, Laptop Charger, Mobile Charger, Receiver Coil, Transmitter Coil, WPT(Wireless Power Transfer)

\section{INTRODUCTION}

Wireless power transfer (WPT) has been demonstrated using various WPT systems, such as Acoustic [1], [2]; Light [3]; Microwave [4]; Laser [5]; Capacitive [6]; and Inductive [7]. The basic layout of all WPT systems is similar. They all consist of a transmitter connected to a primary electronic circuit and a receiver connected to a secondary electronics circuit. The 'medium of power transfer' between receiver and transmitter makes them different from each other. It has been established that an inductive WPT system has the potential to be applied for medium and high power applications, and particularly for the charging of batteries. This method of power transfer has also been referred, contactless power transfer (CPT), contactless energy transfer (CET), inductively coupled power transfer (ICPT), resonant inductive power transfer (RIPT) and inductive power transfer (IPT). Resonant inductive power transfer (IPT) is not a new concept, and many attempts have been made in the past to transmit power wirelessly, most notably by Nikola Tesla $(1856-1943)$ in the late 1800 s and early 1900s. He was inspired by the work of Heinrich Hertz (1857-1984) who first confirmed the existence of electromagnetic radiation in his experiments in 1888. Tesla reported several experimental setups of his WPT

Revised Manuscript Received on June 15, 2019.

Lala Bhaskar, Electronics and Communication Engineering, Amity University, Uttar Pradesh, Noida, India.

Pradeep Kumar, Electronics and Communication Engineering, Amity University, Uttar Pradesh, Noida, India

Kishore Naik Mude, Systec R\&D, Porto, Portugal study using a high-frequency oscillator for medical/therapeutic applications [8]. Figure 1 shows a simplified schematic of one of his experimental setup to power a light bulb wirelessly using RIPT system.

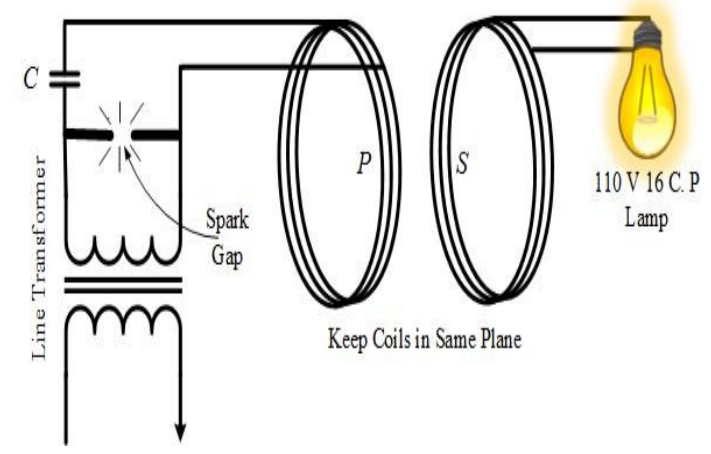

Figure 1 RIPT setup suggested by Tesla[8], [9]

In Figure 1 the circuit contains two loosely coupled and tuned resonant circuits as primary $(\mathrm{P})$ and secondary (S). An external capacitor $\mathrm{C}$ is used to tune the primary while self-capacitance of the solenoid coil is applied to tune the secondary coil. The operating frequency used by Tesla was in the range between 20-100 kHz. Periodic spark gap discharges were used to control the power in the resonant circuit, as the modern resonant converter do today by using power electronic switches. Also, these discharges convert the mains frequency to high frequency of the resonant circuit. It is worth noting that Tesla's experiments were first to demonstrate power transfer using a resonant inductive link and forms the basis of the majority of today's modern wireless power transfer system.

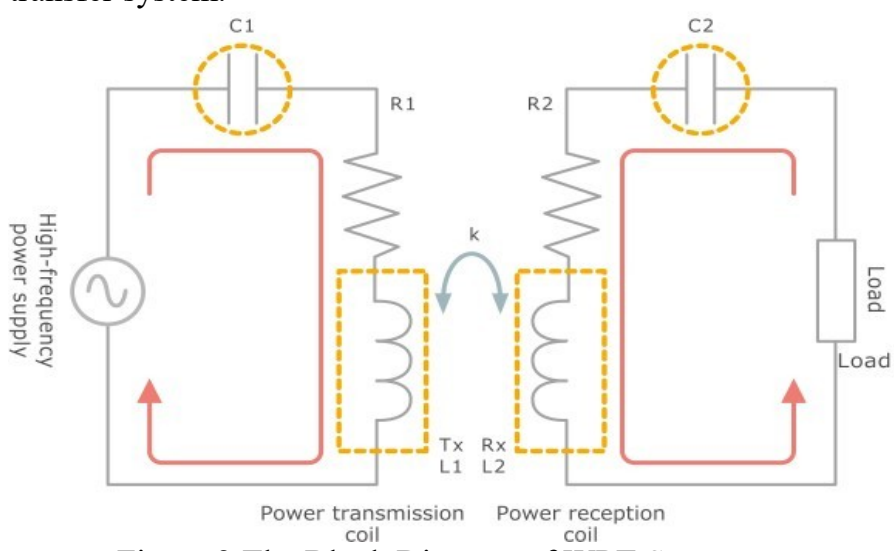

Figure 2 The Block Diagram of WPT System 


\section{Simulation Analysis of Wireless Power Transfer for Future Office Communication Systems}

\section{COIL ANALYSIS}

Accurate physical modeling of the Archimedean spiral (inductor) is important since, once built, it is difficult to modify the spiral. In [10], [11], Wheeler presented several formulas for planar spiral inductors, which were intended for the discrete inductors. In [12], a modified expression of Wheeler formulas was given for spiral, square, hexagonal and octagonal planar coils but it relies on lookup tables. In this paper, an amended form of the original Wheeler formula for an Archimedean spiral coil has been used to calculate the geometric parameters of the spiral coil from the estimated value of self-inductance. Figure 3 shows the representation of an Archimedean spiral.

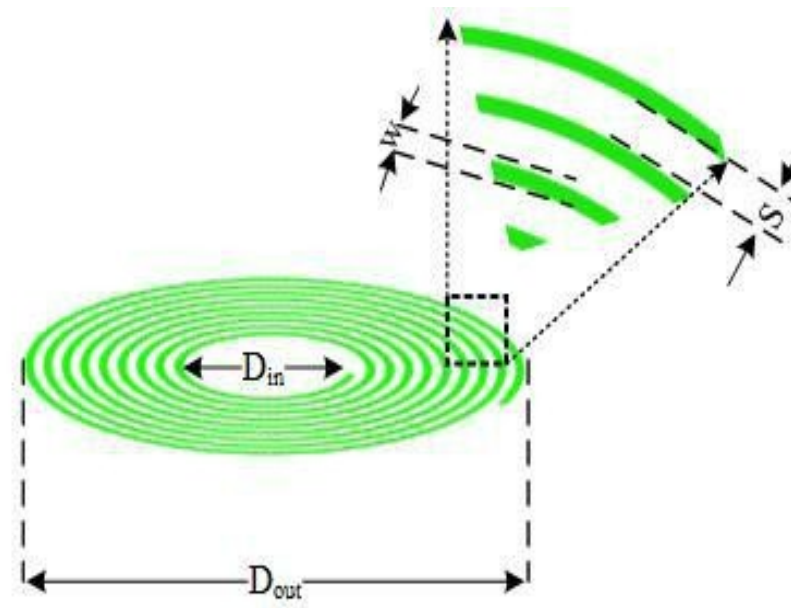

(a)

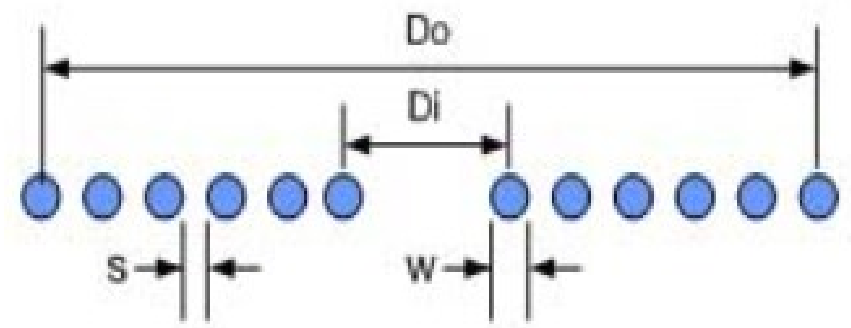

(b)

Figure 3 Physical representation of Archimedean spiral (a) 3-D view [13] (b) Cross-sectional view

The expression for inductance is given as :

$$
\mathrm{L}=\mathrm{N}^{2} \mathrm{~A}^{2} /\left(30 \mathrm{~A}-11 \mathrm{D}_{\mathrm{i}}\right)
$$

$$
\text { Where } A=\left[D_{i}+N(W+S)\right] / 2
$$

From Figure 3 it is obvious that $\mathrm{D}_{\text {out }}$ is the outer diameter, $\mathrm{D}_{\text {in }}$ is inner diameter, $\mathrm{S}$ is the spacing between turns and $\mathrm{W}$ is the diameter of the wire used for making the coil.

\section{Skin Effects:}

For optimal transmission we use high frequencies of input EMF. As a result of frequency increase the depth to which the conduction occurs is reduced by a significant amount given by the formula

$$
\sqrt{\frac{2 p}{w u}}
$$

The solution to our problem is to use stranded wire which reduces skin effect to a considerable amount.

\section{Proximity Effects:}

The distance between two strands of wire (p) should be greater than or equal to 2.5 times of wire thickness $(\mathrm{w})$ $\mathrm{P}>=2.5 \mathrm{~W}$

\section{SIMULATION ANALYSIS}

Simulations have been conducted over Maxwell 3d of Ansys electromagnetic suite. For simulation, a transmission coil and a receiver coil have been made over Maxwell 3d. Both the transmission and receiver coils have a wire of cross sectional diameter 1.5 millimeters, the transmitter coil has 30 turns and the receiver coil has 30 turns. Both the coils have two terminals each extruding from the coils to the face of a region box which is of vacuum, hence the region where the simulation of the coils is conducted is vacuum. Magnetic field simulation has been made over the coils with respect to the vacuum box. The two coils are designed over Ansys electromagnetic suite, where they are identical and both are of copper. The color difference is only to identify the difference between the transmitter and the receiver coils. The following parameters have been considered for designing the both the primary and secondary coils as $\mathrm{D}_{\mathrm{i}}=50 \mathrm{~mm}, \mathrm{~N}=30, \mathrm{~W}=1.5 \mathrm{~mm}$, $\mathrm{S}=0.2 \mathrm{~mm}$ and $\mathrm{D}_{0}=152 \mathrm{~mm}$

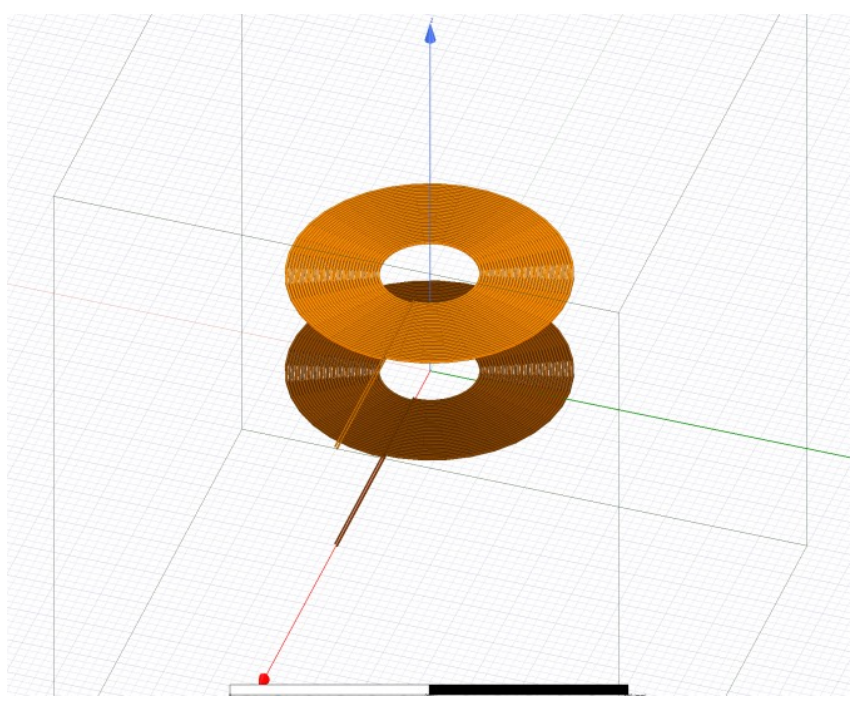

Figure 4 Transmission and receiver coils in Alignment (with terminals)

The designed coils are placed in a circuit made on Twin Builder by Ansys as shown in figure 5. From the figure 5 it can be seen that two watt meters are placed in the circuit to measure the input and output power. The capacitances are selected in accordance with the input resonance frequency. The resistances are selected as standard $100 \mathrm{ohms}$. 


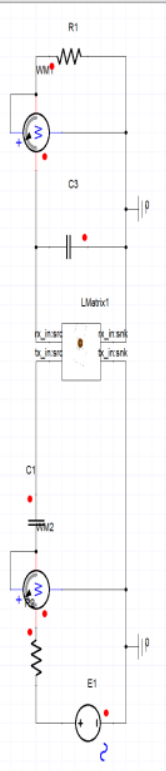

Figure 5 Schematic of Circuit made on Twin Builder

Initially the distance between the primary to secondary coil is taken as $5 \mathrm{~mm}$ and the input frequency is $40 \mathrm{kHz}$. Theoretically the inductance is calculated as $93.64 \mu \mathrm{H}$ and the simulated mutual inductance is $177.47 \mu \mathrm{H}$ (adjusted to the material and the effect of addition of terminals). The coupling coefficient is 0.9164 which is almost best in class for very efficient wireless power transfer. Using Twin builder the power output is calculated as $87.8 \mathrm{~W}$ which provides fast wireless charging of a device.

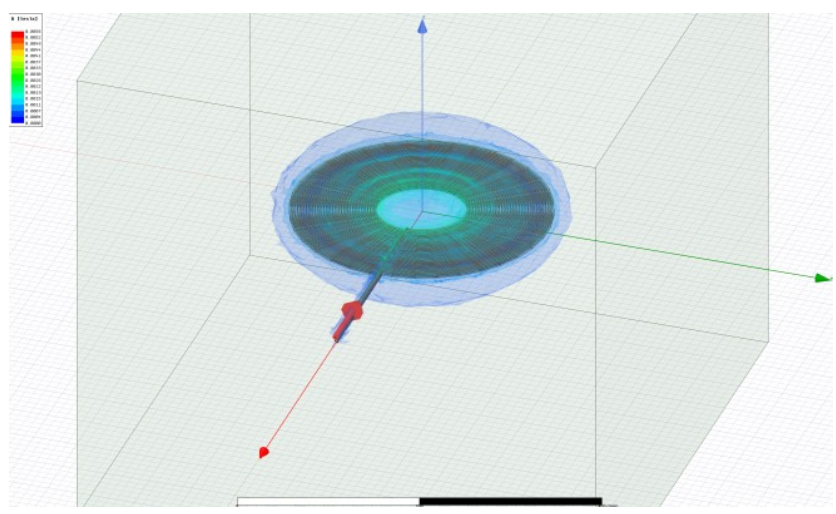

Figure 6 Magnetic Field between coils at $5 \mathrm{~mm}$ enclosed in a vacuum box

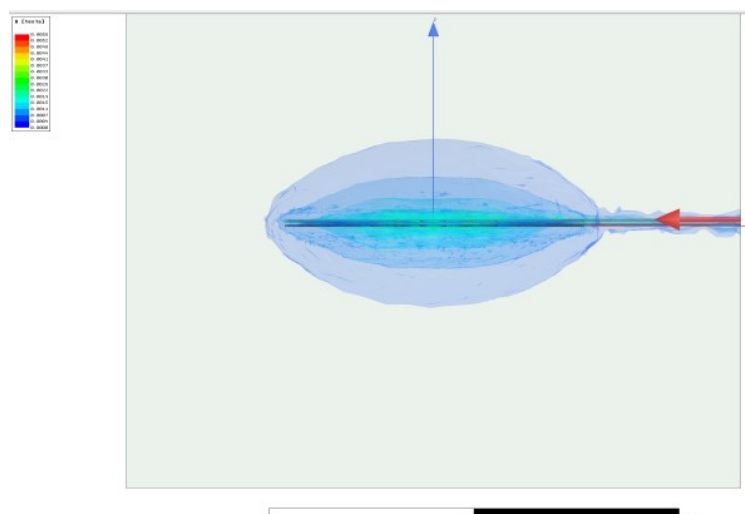

Figure 7 Lateral closed view of Magnetic Field density at $5 \mathrm{~mm}$ $\begin{array}{rrr}\text { |Matrix1.L(rx_in,rx_in) [uH] } & \text { Matrix1.L(tx_in,rx_in) [uH] } & \text { Matrix1.L(tx_in,tx_in) [uH] } \\ 177.3421544 & 162.5707138 & 177.4091405\end{array}$

\section{Power Output at O5mm distance}

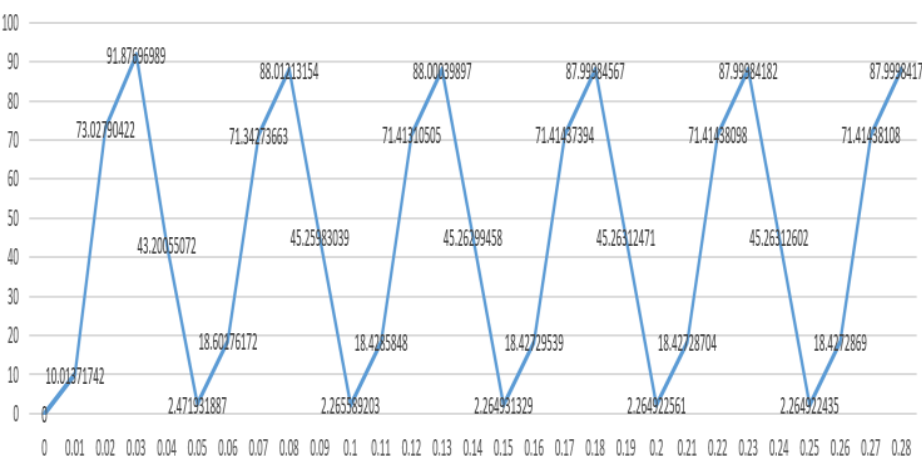

Figure 8 Power Output received at $5 \mathrm{~mm}$ distance

Now the distance between the primary and secondary is increased to $30 \mathrm{~mm}$ and the simulated mutual inductance is given $103.98 \mu \mathrm{H}$ and the coupling coefficient is 0.585 . The coupling coefficient is very respectable for wireless power transfer. Using the Twin builder the power output is calculated as $33.14 \mathrm{~W}$ which is very respectable for charging of a device with a thick outer shell or base.

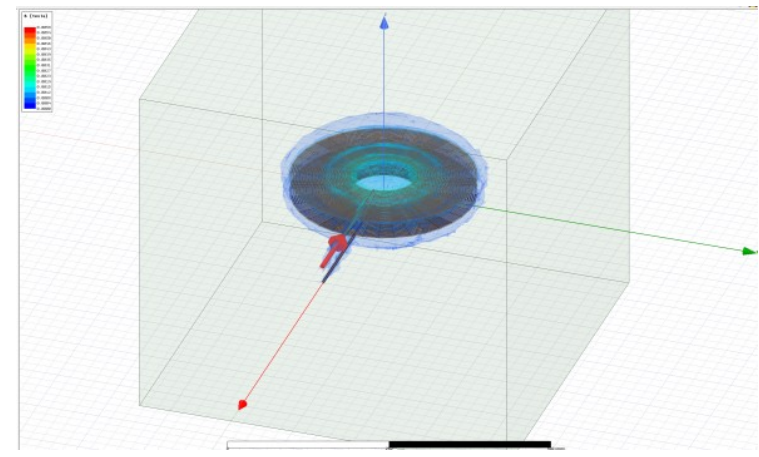

Figure 9 Magnetic Field between coils at $30 \mathrm{~mm}$ enclosed in a vacuum box

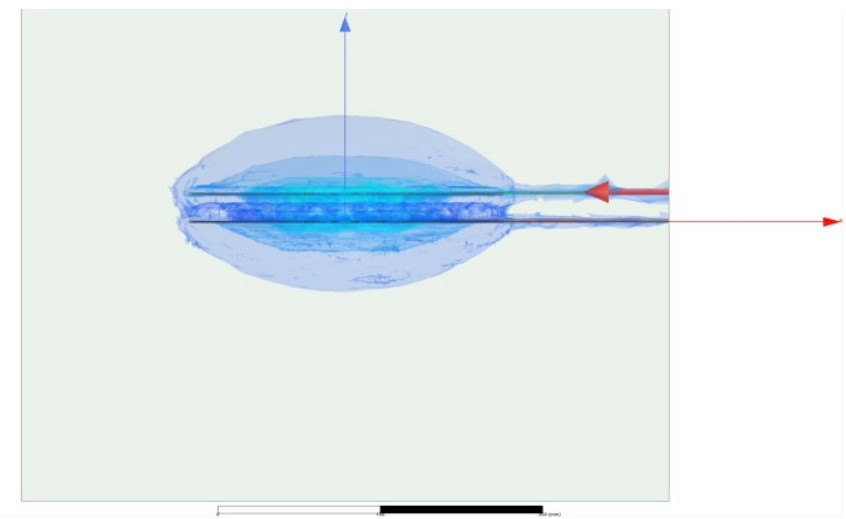

Figure 10 Lateral closed view of Magnetic Field density at 30mm 
$\begin{array}{rrr}\text { Matrix1.L(rx_in,rx_in) [uH] } & \text { Matrix1.L(tx_in,rx_in) [uH] } & \text { Matrix1.L(tx_in,tx_in) [uH] } \\ 177.4984799 & 103.9882015 & 177.7764809\end{array}$

Power Output at 30 mm of distance

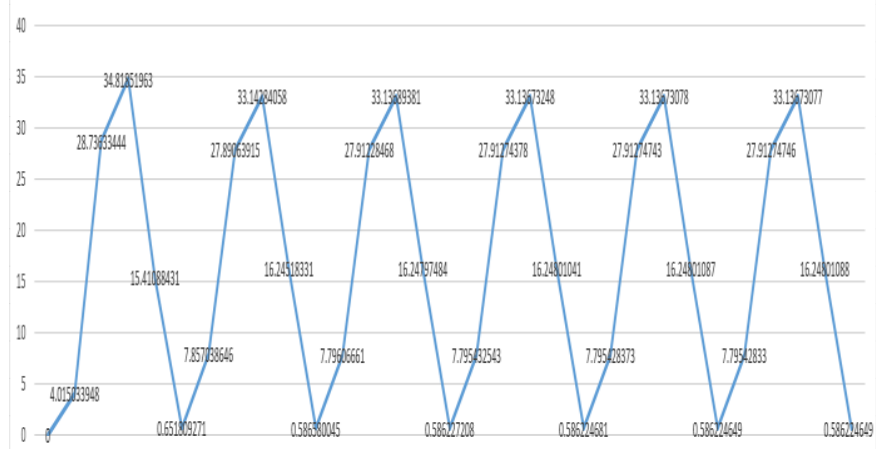

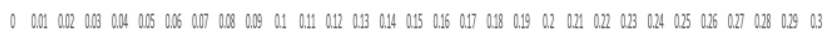

Figure 11 Power Output received at 30mm distance

The distance between the primary coil and the secondary coil is further increased up to $100 \mathrm{~mm}$ and the coupling coefficient is 0.195 . The output power is $3.5 \mathrm{~W}$ but when the input is adjusted to 3 times the regular input the output is obtained around $35 \mathrm{~W}$.

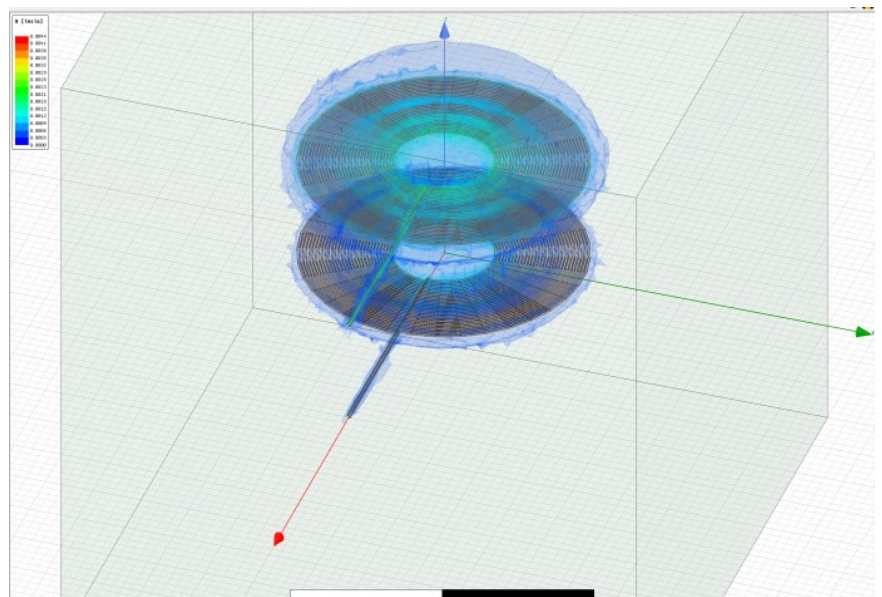

Figure 12 Magnetic Field between coils enclosed in a vacuum box

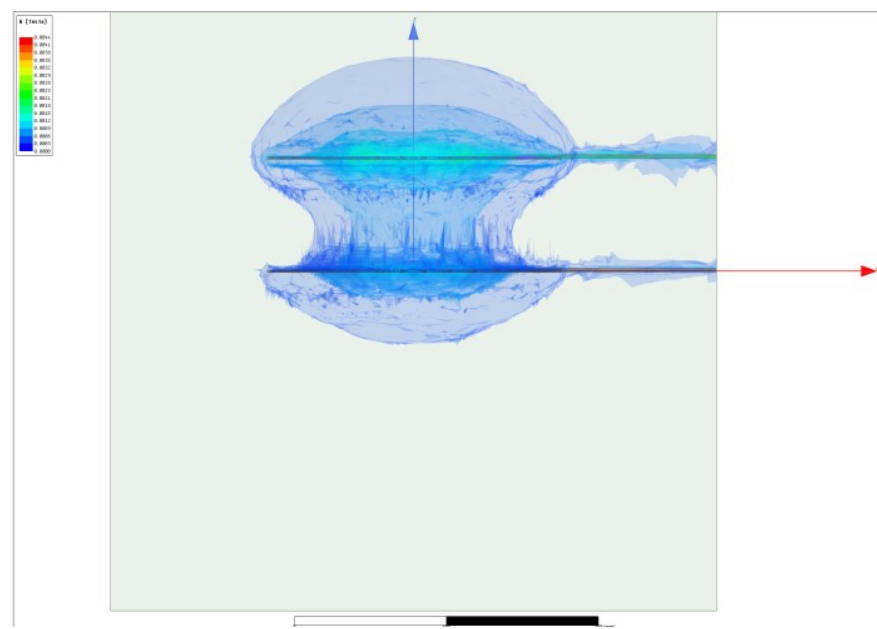

Figure 13 Lateral closed view of Magnetic Field density
Power Output at 100mm distance

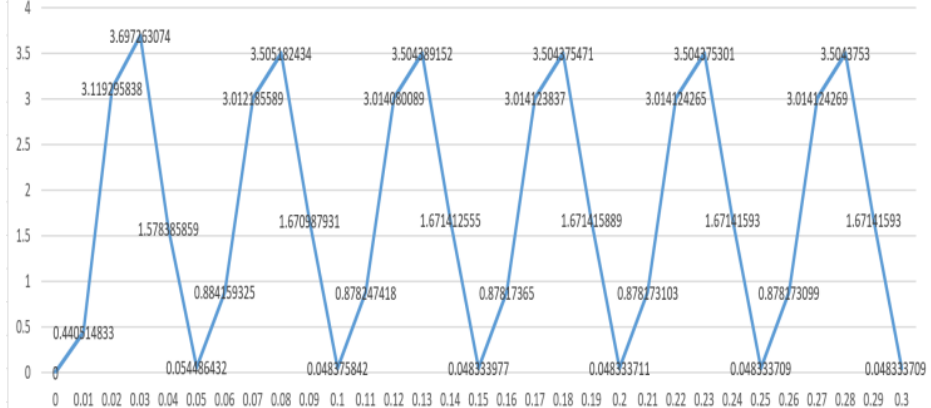

Figure 14 Power Output received at $100 \mathrm{~mm}$ distance

Table 1 Power Output in Secondary coil with respect to distance

\begin{tabular}{|l|c|c|c|}
\cline { 2 - 4 } \multicolumn{1}{c|}{} & \multicolumn{3}{c|}{ Distance } \\
\cline { 2 - 4 } \multicolumn{1}{c|}{} & $5 \mathrm{~mm}$ & $30 \mathrm{~mm}$ & $100 \mathrm{~mm}$ \\
\hline Mutual Inductance & $177.47 \mu \mathrm{H}$ & $103.98 \mu \mathrm{H}$ & $34.62 \mu \mathrm{H}$ \\
\hline Coupling coefficient & 0.9164 & 0.585 & 0.195 \\
\hline Output Power & $87.8 \mathrm{~W}$ & $33.14 \mathrm{~W}$ & $3.5 \mathrm{~W}$ \\
\hline
\end{tabular}

As per the table1 the output power received in the secondary coil having enough power to charge or drive the Office communication systems like Laptops, monitors, mobile phones, printers.

The input frequency is varied from $1 \mathrm{kHz}$ to $120 \mathrm{kHz}$ and the respective resonant capacitance values are calculated and put in the circuit of Twin builder. It can be seen from the figure 15 that input frequency between $20 \mathrm{kHz}$ to $30 \mathrm{kHz}$, the output

\section{PowerOutput Vs Resonant Frequency}

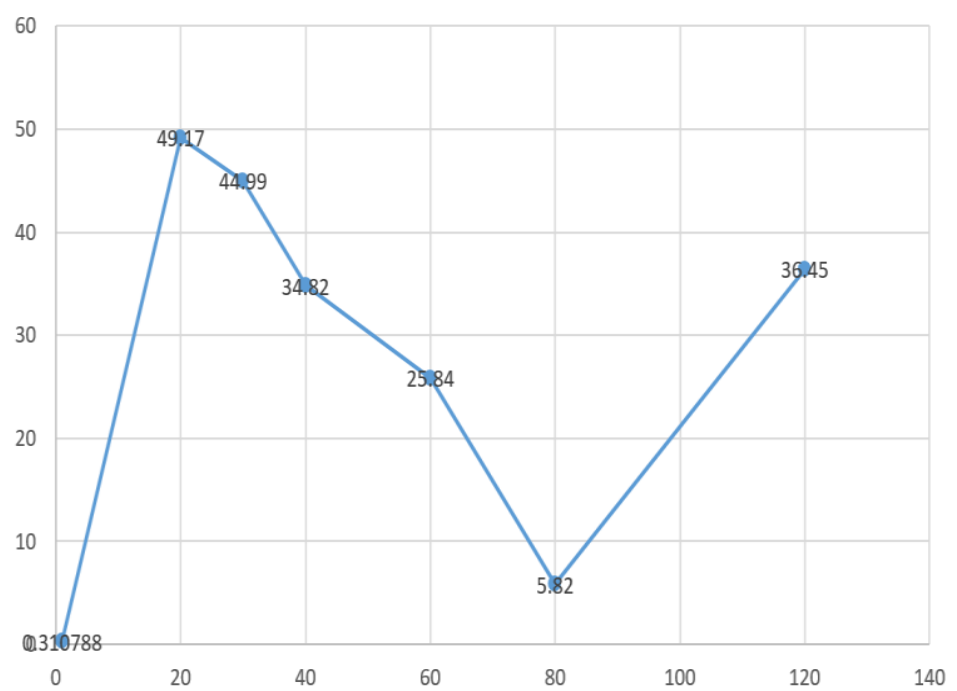

Figure 15 Power output Vs Resonant frequency

Published By: 
power appears to be maximum, with all the other parameters fixed. So far the simulations were performed with input frequency $40 \mathrm{kHz}$. Now the input frequency is taken as intermediate of $20 \mathrm{kHz}-30 \mathrm{kHz}$ and is $25 \mathrm{kHz}$ of resonance frequency. Now the simulations have performed with $25 \mathrm{kHz}$ input frequency for same coil parameters with coil distance of $30 \mathrm{~mm}$. The simulated mutual inductance is given $103.98 \mu \mathrm{H}$ and the coupling coefficient is 0.585 . The coupling coefficient is very respectable for wireless power transfer.

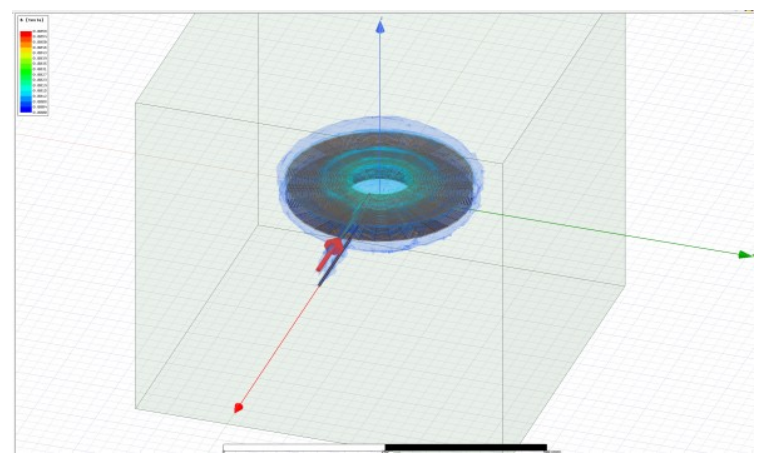

Figure 16 Magnetic Field between coils at $30 \mathrm{~mm}$ enclosed in a vacuum box

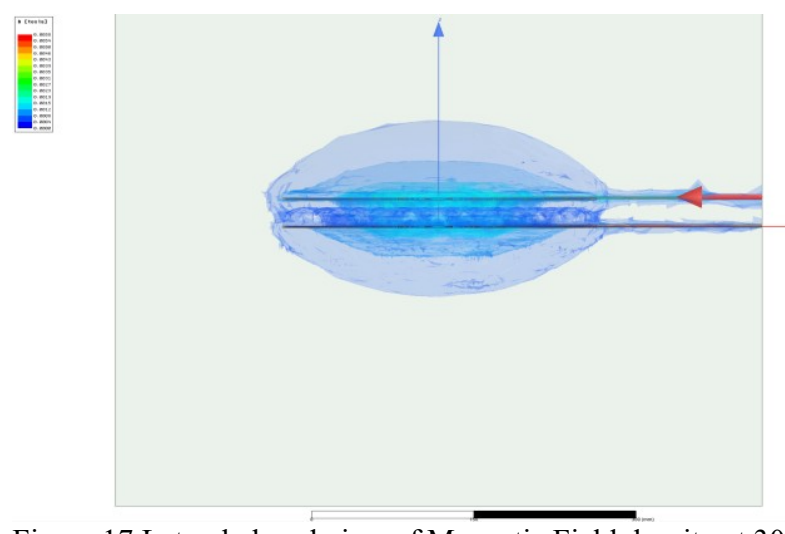

Figure 17 Lateral closed view of Magnetic Field density at 30mm

Output Power at 25kHz

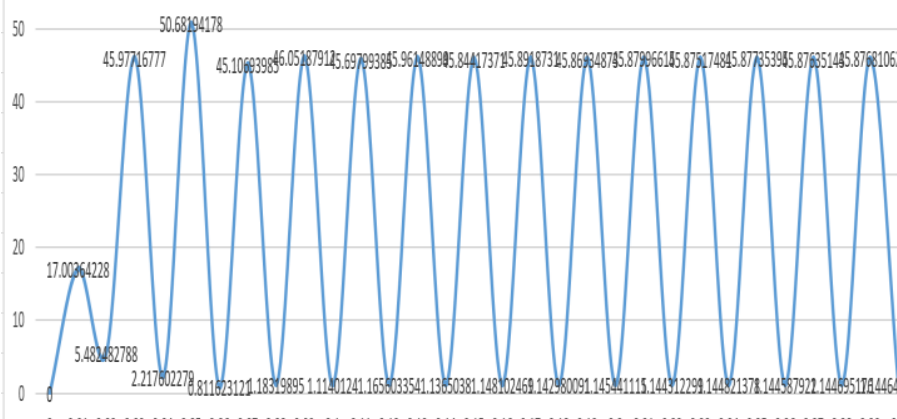

00.010 .220 .030 .040 .050 .0600 .700 .80 .0900 .10 .110 .120 .130 .140 .150 .160 .170 .180 .190 .20 .210 .220 .230 .240 .250 .260 .270 .280 .29

Figure 18 Power Output received at $30 \mathrm{~mm}$ distance

Using Twin Builder the power output is calculated as $45.8 \mathrm{~W}$ which is very respectable for charging of a device using wireless power transfer technique. There is an improvement of $72 \%$ in the output power over the previously taken input frequency $40 \mathrm{kHz}$. Hence $25 \mathrm{kHz}$ input frequency is better suitable for proposed coil design.

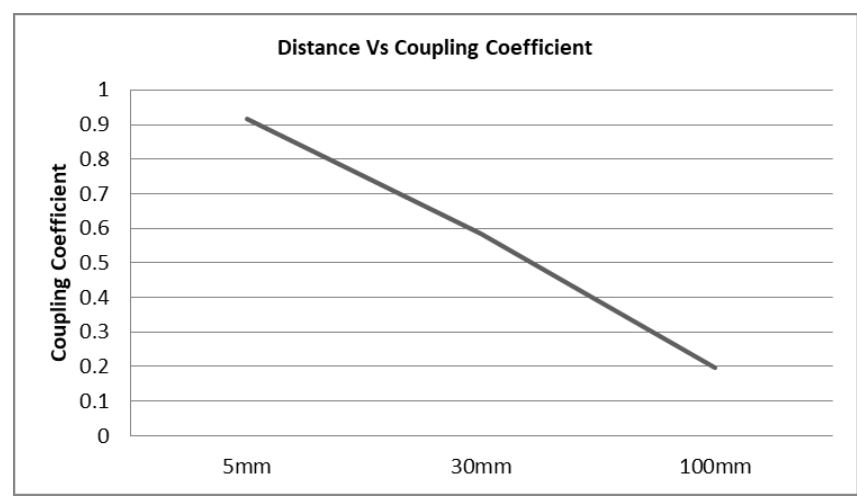

Figure 19 Distance vs Coupling coefficient

As per the data from Table 1, distance vs coupling coefficient is plotted and is shown in Figure 19. The coupling coeffiecent between coils descreases as the distance betweenthe coils increases.

\section{CONCLUSION}

The simulation analysis of Wireless Power Transfer for office communications has performed using the over Maxwell $3 \mathrm{~d}$ of Ansys electromagnetic suite. As per the simulation results the output power received in the secondary coil having enough power to charge or transmit the power to the Office communication systems like Laptops, monitors, mobile phones, printers. The simulations were performed at variable distances between transmitter coil and receiver coil as $5 \mathrm{~mm}$ to $100 \mathrm{~mm}$. As per the results it has been observed that the input frequency of primary coil between $20 \mathrm{kHz}$ to $30 \mathrm{kHz}$, the output power appears to be maximum with all the other parameters fixed. There is an improvement of $72 \%$ seen in the output power of secondary coil for $25 \mathrm{kHz}$ input frequency of primary coil over the input frequency of $40 \mathrm{kHz}$. Hence the 25 $\mathrm{kHz}$ input frequency is best suitable for the proposed model of coil parameters.

\section{REFERENCES}

1. M. G. L. Roes, J. L. Duarte, M. A. M. Hendrix and E. A. Lomonova, "Acoustic Energy Transfer: A Review," IEEE Trans. on Industrial Electronics, vol. 60, no. 1, Jan. 2013, pp. 242-248.

2. Y. Hu, X. Zhang, J. Yang and Q. Jiang, "Transmitting electric energy through a metal wall by acoustic waves using piezoelectric transducers," IEEE Trans. on Ultrasonics, Ferroelectrics, and Frequency Control, vol 50, no. 7, July 2003, pp. 773-781.

3. A. Sahai and D. Graham, "Optical wireless power transmission at long wavelengths," in Proc. International Conference on Space Optical Systems and Applications, Santa Monica, CA, 2011, pp. 164-170.

4. S. Sasaki, K. Tanaka and K. i. Maki, "Microwave Power Transmission Technologies for Solar Power Satellites," in Proc. of the 5 IEEE, vol. 101, no. 6, June 2013, pp. 1438-1447.

. L. Summerer and O. Purcell, "Concepts for Wireless Energy Transmission via Laser," 2008.

6. J. Dai and D. C. Ludois, "A Survey of Wireless Power Transfer and a Critical Comparison of Inductive and Capacitive Coupling for Small Gap Applications," IEEE Transactions on Power Electronics, vol. 30, no. 11, Nov. 2015, pp. 6017-6029.

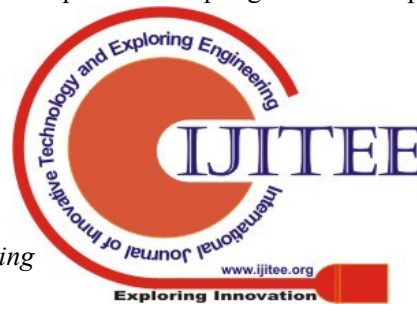


7. G. a. Covic and J. T. Boys, "Inductive Power Transfer," Proc. IEEE, vol. 101, no. 6, 2013, pp. 1276-1289.

8. N. Tesla, "High frequency oscillators for lectro-therapeutic and other purposes," in Proc. IEEE, vol. 87, no. 7, 1999, pp. 1282-1292.

9. S. Y. R. Hui, "Magnetic Resonance for Wireless Power Transfer [A Look Back]," IEEE Power Electronics Magazine, vol. 3, no. 1, March 2016, pp. 14-31.

10. H. A. Wheeler, "Simple Inductance Formulas for Radio Coils," in Proceedings of the Institute of Radio Engineers, vol. 16, no. 10, Oct. 1928, pp. 1398-1400.

11. H. A. Wheeler, "Inductance formulas for circular and square coils," in Proceedings of the IEEE, vol. 70, no. 12, Dec. 1982, pp. 1449-1450.

12. S. S. Mohan, M. del Mar Hershenson, S. P. Boyd and T. H. Lee, "Simple accurate expressions for planar spiral inductances," in IEEE Journal of Solid-State Circuits, vol. 34, no. 10, Oct 1999, pp. 1419-1424.

13. Kunwar Aditya, Sheldon S. Williamson "Design Guidelines to Avoid Bifurcation in aSeries-Series Compensated Inductive Power Transfer System IEEE Transactions on Industrial Electronics, vol.66, no.5, May 2019.

\section{AUTHORS PROFILE}

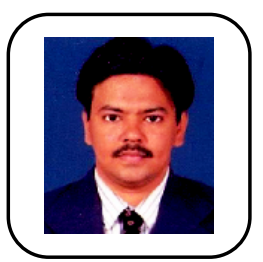

Lala Bhaskar received the M.Tech. degree from Guru Gobind Singh Indraprastha University, Delhi, India, in 2008. He is currently working as an Assistant Professor in the Department of Electronics and Communication Engineering, Amity University Uttar Pradesh, Noida, India. He is pursuing his Ph.D. from AIIT, AUUP, Noida and has 10 years of teaching experience, most recently focusing on Wireless Power Transfer Systems, VLSI, Embedded and IoT applications, design and verification using Verilog and System Verilog. He has published more than 10 research papers in international Journals/conferences.

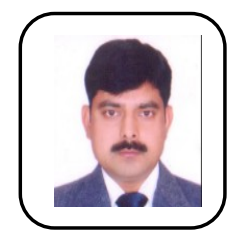

Dr Pradeep Kumar is currently working as an Associate Professor in the Department of Electronics and Communication Engineering, Amity University Uttar Pradesh, Noida, India. He has received his Ph. D. degree from Garhwal University Srinagar (Garhwal) Uttaranchal, India, in 2006. Dr Kumar's has 14 years of teaching and research experience, most recently focusing on VLSI, microelectronics, device modelling and simulation, design and verification using Verilog and system verilog. He has published more than fifty research papers in national and international Journals/conferences.

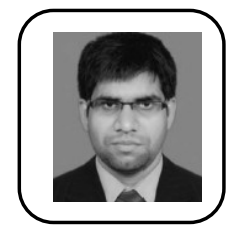

Dr Kishore Naik Mude received the B.Tech. degree from Sri Venkateswara University, Tirupati, India, in 2008, the M.Tech. degree from the Motilal Nehru National Institute of Technology, Allahabad, India, in 2010, and the Ph.D. degree from the University of Padova, Padova, Italy, in March 2015, all in electrical engineering. From 2010 to 2011, he was a Lecturer with Amity University, Noida, India. From 2015 to 2016, he was an Assistant Professor with Amrita Viswa Vidya Peetam University, Bengaluru Campus, Bengaluru, India. He is currently working in Systec R\&D, Porto, Portugal. His current research interests include wireless power transfer for electrical vehicles and power electronics. 